\title{
A INFORMAÇÃO: UM RECURSO DA GESTÃO
}

\author{
Helena Isabel Barroso Saraiva*
}

\begin{abstract}
O presente artigo alude às circunstâncias em que actualmente a gestão das organizações se desenrola, numa sociedade denominada da informação, onde a chave para o sucesso passou, em grande parte, a residir na capacidade de receber, armazenar e difundir informações de modo eficiente e em tempo oportuno.

$O$ cenário de turbulência em que as organizações actuam implica o aumento da quantidade de problemas não estruturados e a informação deve então ser encarada como um suporte da decisão, mas também um envolvente dessa decisão e algo que a condiciona, ou seja, como um recurso de gestão. Ela aparece como uma parte integrante dos processos de gestão. No entanto não pode ser tomada como uma entidade abstracta: a organização deverá definir o que é para ela a informação de valor estratégico para o seu negócio.

Consequentemente, a informação deve passar a ser encarada como um recurso em termos económicos e, tal como os outros recursos, ela tem que ser gerida. Ou seja, a gestão das organizações é, actualmente, mais que qualquer outra coisa, trabalhar e processar informação.
\end{abstract}

\section{INTRODUÇÃO}

Vivemos, como é comum afirmar-se hoje em dia, numa sociedade da informação, onde a chave para o sucesso passou, em grande parte, a residir na capacidade de receber, armazenar e difundir informações de modo eficiente e em tempo oportuno.

\footnotetext{
* Professora Adjunta no Instituto Politécnico da Guarda.
} 
Portugal, país periférico relativamente aos centros de decisão efectivos, que são também os centros de poder económico e, simultaneamente, os detentores da informação útil $\mathrm{e}$ indispensável ao progresso $\mathrm{e}$ ao desenvolvimento, não pode deixar de considerar a "revolução da informação" como um desafio fundamental e decisivo para o seu próprio desenvolvimento enquanto vector correlacionado e indissociável de um processo de modernização e desenvolvimento das estruturas produtivas. Este processo constitui, a curto prazo, uma grande aposta para a economia portuguesa, implicando, simultaneamente, uma profunda modificação na forma como alguns sectores ainda encaram a gestão dos seus negócios.

Tudo isto porque a "nova ordem" reinante no mundo da economia e da gestão implica que sejam absorvidas as grandes inovações tecnológicas, numa lógica de adaptação e ajustamento às características e às necessidades específicas do nosso país e das suas diferentes regiões.

Esta tarefa é, naturalmente, meta a atingir para as estruturas produtivas do país e também para os organismos ligados à investigação e ao desenvolvimento e aqueles que se queiram assumir como pólos indutores do desenvolvimento económico e social, tais como as universidades, os institutos politécnicos e as associações empresariais. Será também meta a atingir para os organismos vocacionados para a problemática das PME's, pois o peso destas no tecido industrial português justifica a criação de centros de informação. Não será necessário acrescentar todas as limitações e dificuldades que as PME's teriam para suportar, pelos seus próprios meios, uma estrutura deste tipo.

\section{INFORMAÇÃO E GESTÃO}

O cenário de turbulência que caracteriza o contexto actual, em que as empresas e organizações têm que sobreviver, tende a aumentar a quantidade de problemas não estruturados. Neste contexto "a qualidade da gestão resulta de uma combinação de sorte, intuição e razão, alimentada por informação fiável e oportuna" (Zorrinho, 1991).

A informação deve então ser encarada como um suporte da decisão, mas também um envolvente dessa decisão e algo que a condiciona: como um recurso de gestão.

Segundo Mcpherson (1995), a percepção de que conhecimento e informação constituem a traç̧ão fundamental para o crescimento económico, quer a nível nacional, quer a nível empresarial, está a começar a permear o pensamento económico e de gestão. Para este autor, o factor essencial do crescimento económico, na actualidade, é dado pelo poder da mente humana 
de aplicar conhecimento e informação no sentido de obter vantagens competitivas. Mantém essa tónica nos conceitos de uma economia do conhecimento e de um capitalismo de informação subjacentes às novas economias e negócios baseados na informação.

Para Santos (1992), uma das partes integrantes do planeamento estratégico actual é a «criação de um sistema de informação, quantitativo e qualitativo, eficiente e on-line».

É óbvio que, para estes autores, a informação aparece, hoje em dia, como uma parte integrante e indispensável dos processos de gestão modernos. No entanto, a informação não pode ser tomada como uma entidade abstracta que determina o sucesso ou insucesso de uma empresa ou organização, mas a organização deverá definir o que é para ela informação, ou seja, o que é que constitui informação de valor estratégico para o seu negócio.

\section{O CONCEITO DE INFORMAÇÃO}

Independentemente do sentido dado ao termo, pode afirmar-se que informação existiu em todos os momentos e em todas as sociedades. Mesmo assim, $e$ indiscutível que a sociedade actual se encontra cada vez mais dependente da informação. E é como consequência desta realidade que a informação tende a ser cada vez mais encarada pelas organizações como um recurso e simultaneamente um meio de competir no mercado.

Como afirmava um importante autor de temas de gestão, já em 1988: «O que será o "governo do futuro", permanece ainda como uma vasta especulação. Mas a organização do futuro está rapidamente a tornar-se realidade - uma estrutura na qual a informação serve de eixo e como estrutura central de apoio.» (Drucker, 1988, p. 183).

Procurando uma definição do conceito de informação, recorremos a alguns autores que o interpretam de diversos modos:

- segundo Rigaud ( $\mathrm{s} / \mathrm{d})$, «a informação designa o conteúdo das trocas do homem com o meio que o rodeia para facilitar a sua adaptação»; e vai ainda mais longe, ao afirmar que os significados normalmente atribuídos à palavra informação contêm, frequentemente, os seguintes elementos:

- a negação da dúvida (afirmando que quando a dúvida se anula não existe informação suplementar);

- a relação com a liberdade de escolha (estar informado é conhecer um conjunto de alternativas ou de possibilidades de escolha); 
- a manutenção da organização (entendendo os organismos como sendo constituídos por elementos essencialmente ligados pelas informações que transmitem entre si);

- a ligação e a troca (as trocas de informação com o exterior permitem a evolução e a adaptação da organização);

- Drucker (1989), por sua vez, afirma que «informação são dados dotados de relevância e propósito»;

- para Zorrinho (1991), «a informação é um modelo de representação do real, conjugando registos em código convencionado, de acontecimentos, objectos ou fluxos que constituem esse real perceptível, segundo um determinado padrão de associação e selecção» (Zorrinho, 1991, p. 18).

Não é nosso objectivo discutir o conceito de informação, mas apenas tentar clarificar o que se deve entender por informação sempre que se utilizar o termo no contexto deste artigo. Isto porque o conceito de informação é bastante difuso e controverso: segundo Yuexiao (1988), o conceito surge em numerosas obras e a sua definição sofre muitas diversificações.

Este autor refere existirem mais de $\mathbf{4 0 0}$ definições do conceito. No entanto, aponta $\circ$ facto de, na linguagem comum, a palavra informação poder significar: «mensagens, notícias, dados, conhecimento, documentos, literatura, entendimento, símbolos, sinais, ideias, indicações, e o que é reunido por algumas agências especiais como a CIA e o KGB» (Yuexiao, 1988, p. 479).

Citando novamente Drucker, a informação é um dos elementos privilegiados da gestão num ambiente em constante mudança, como é o do mundo actual. Esta ideia é hoje largamente difundida e até talvez geralmente aceite. No entanto, muitas pessoas encaram o conceito de informação, ou de organização baseada na informação, como um tipo de organização que depende totalmente do uso de tecnologias de informação ou tecnologias avançadas.

Esta ideia está também ligada à de que a simples adopção de tecnologias de informação é garante de vantagens competitivas para a organização que as adopta, independentemente de essa adopção apenas gerar as oportunidades de as obter. Parece-nos claro que a obtenção efectiva dessas vantagens dependerá das utilizações daquelas tecnologias.

Aos responsáveis pela organização baseada na informação deve apenas perguntar-se:

- quem requer a informação?

- qual informação?

- quando?

- onde? 
E, a par disto, devem considerar-se as tecnologias como meros instrumentos para alcançar os objectivos e metas a atingir, tanto pela organização como um todo, como por cada uma das pessoas que compõem essa organização: conhecendo-se, assim, quem são os utilizadores internos (dentro da organização) e externos (no exterior da organização) da informação que é gerada por cada pessoa/função, assim como as fontes utilizadas (internas e externas) por essa pessoa/função.

\section{A INFORMAÇÃO COMO RECURSO}

Mais do que nos anteriores tipos de sociedade, a informação atingiu na actualidade um papel fundamental na vida dos indivíduos e das comunidades em que estes se integram. Como consequência dos desenvolvimentos ocorridos relativamente às Tecnologias da Informação e da Comunicação, assiste-se a um aumento da informação produzida e transmitida e o seu papel passou a ser determinante no processo de tomada de decisão dos indivíduos, à escala individual e profissional.

Como consequência desse enorme aumento da quantidade de informação disponível, surge um outro problema: qual a informação de valor estratégico para a vida das pessoas e das empresas?

A resposta a esta questão leva a que, consequentemente, essa informação tenha que passar a ser encarada como um recurso em termos económicos, tal como o capital, a mão-de-obra e a terra. E tal como os outros recursos, ela tem que ser trabalhada, processada, seleccionada, escolhida, de forma a não nos deixarmos "submergir" por todo um conjunto de informação irrelevante, desnecessária e indesejável e que terá custos monetários. No caso das organizações, esses custos podem ser substanciais, pelo que não surpreende que as mesmas estejam cada vez mais atentas a este facto.

A gestão de qualquer organização deve ter em conta que, para cumprir as suas tarefas, controlo das operações e a contribuição para a consecução dos objectivos organizacionais têm de ser auxiliados e alimentados por informação variada, mas que obedeça aos requisitos necessários à prossecução do negócio da organização. E essa informação deve ser gerida de forma a que a aquisição dessa variedade de informação, a sua categorização, armazenamento, comunicação e distribuição aos utilizadores, façam parte integrante do próprio ciclo de gestão (Mcpherson, 1995).

Para Zorrinho (1995), "a muito proclamada Sociedade da Informação, ou seja, o sistema socioeconómico, caracterizado por ter na informação o seu recurso estruturante, exige novas práticas e novos conceitos de gestão empresarial" (Zorrinho, 1995, p. 145). 
Poder-se-á afirmar que é através da informação que as empresas comunicam com o meio envolvente, detectam as necessidades existentes, assim como os condicionalismos e as oportunidades para a sua acção e dão a conhecer aquilo que têm para oferecer.

No entanto, a informação pode ser também utilizada pelas organizações para se prepararem para competir, para adquirir conhecimentos úteis para o seu funcionamento e para reter dados importantes da sua experiência.

Ou seja gerir é, actualmente, mais que qualquer outra coisa, trabalhar e processar informação. É com base em informação que os elementos da empresa decidem e essas decisões dão, por sua vez, origem a mais informação. Esta situação implica que a condição prévia, anterior a qualquer proposta de intervenção ou tomada de decisão por parte das organizações, seja o conhecimento da informação crítica para essa decisão assim como a sua avaliação.

Os objectivos alcançados pelas mesmas decorrem das percepções assumidas relativamente à importância da informação como recurso valioso e indispensável, não só para as organizações como também para a própria sociedade.

Uma das preocupações primordiais para as organizações de tipo empresarial será precisamente a obtenção dos recursos de informação, através da análise do funcionamento dos vários departamentos que as compõem, assim como da inventariação dos recursos de informação existentes interna e externamente.

Por outro lado, o facto da informação ser encarada como um recurso pode até ser tomado como ponto de partida para o incremento da gestão da informação, ao nível da definição da estratégia da organização.

Esta perspectiva, relativamente à qual se pretende alertar as organizações, é a da possibilidade da informação poder ser usada, estrategicamente, como factor competitivo e de posicionamento no mercado.

Isto pode significar que a organização possa basear a sua actuação na recolha e tratamento de informação que constitua uma vantagem comparativa, relativamente a outras organizações do género, alimentando sistemas estratégicos de informação.

No entanto, se é evidente que todas as organizações têm implícita ou explicitamente um sistema que lhes fornece informação para actuar, assim como sobre a sua actuação, não é tão evidente que grande parte das organizações estabeleça claramente, quer a existência, quer o papel, quer ainda o alcance desse sistema.

Segundo Zorrinho (1995), «a informação é um recurso, cujos contornos se definem pelo uso que dela se faz»; o autor define também mercado de informação ao afirmar: «é mercado da informação o conjunto de transações de informação feitas com o objectivo directo de consumo pelas empresas e outras 
organizações e pelos seus membros no exercício das suas funções» (Zorrinho, 1995, p. 122).

Assim, pode afirmar-se que, actualmente, a informação se apresenta como um factor económico chave que deve ser gerido, sendo encarado como um recurso, mas pode sê-lo também como um serviço, uma fonte de valor acrescentado e uma fonte de emprego.

\section{BIBLIOGRAFIA}

BANGEMANN et al (1994), A Europa e a Sociedade da Informação. Relatório apresentado ao Conselho Europeu, Bruxelas, Comissão Europeia.

BEST, D. P. (1988), "The Future of Information Management", International Journal of Information Management, V. 8, $\mathrm{n}^{\circ} 1, \mathrm{p} .13$.

DRUCKER, Peter F. (1988), As fronteiras da Gestão, Lisboa, Editorial Presença.

DRUCKER, Peter F. (1989), As novas realidades no governo e na política, na economia e nas empresas, na sociedade e na visão do mundo, São Paulo, Enio Matheus Guazzelli \& Cia. Ltda..

FERNANDES, António José (1994), Métodos e regras para elaboração de trabalhos Académicos e Científicos, Porto, Porto Editora.

HORTON, F. W. (1985), Information Resources Management, Englewood Cliffs, Prentice Hall.

MCPHERSON, P. K. (1995), Information Mastery. Managing Information, 2: 6, p. 33-36.

NORTON, Bob (1992), «Sources and Uses of Business Information», Aslib Proceedings, 44 (4), p. 165-172.

RIGAUD, L. (s/d), Os Sistemas de Informação na Empresa, Porto, Rés Editora.

SANTOS, Francisco Lopes dos (1992), Excelência Estratégica, Lisboa, Autor.

SYNOTT, W. R. (1987), The Information Weapon: winning Customers and Markets with Technology, New York, Wiley.

YUEXIAO (1988), "Definitions and Sciences of Information", Information Processing \& Management, V. 24, $\mathrm{n}^{\circ} 4$, p. 479-491.

WILSON, T. D. (1989), “Towards an Information Management Curriculum”, Journal of Information Science, V. 15, $\mathrm{n}^{\circ} 415$, p. 203-209.

ZORRINHO, Carlos (1991), Gestão da informação, Lisboa, Editorial Presença.

ZORRINHO, Carlos (1995), Gestão da informação condição para vencer, Lisboa, Instituto de Apoio às Pequenas e Médias Empresas e ao Investimento. 